ISSN (Print) : :1412-7601

ISSN (Online) : 2654-8712

Volume 5, No.1 Maret 2019

EKONOBIS

http://www.ekonobis.unram.ac.id

\title{
Analisis Kebutuhan Sarana Dan prasarana di Kecamatan Selong Sebagai Pusat Pertumbuhan Di Kabupaten Lombok Timur
}

\author{
M.Alwi, Ade Paranata, PutuKarismawan.
}

Universitas Mataram

A R T I C L E I N F O Received : 8Januari 2019; Accepted: 20Februari 2019; Published: Maret 2019

Keywords :

Educations and health

infrastructure needs

ABSTRACT : The purpose of this study is to analyze the current conditions (2016) and to project educational and health infrastructure needs in the Selong District of East Lombok Regency until 2022. The data used is a quantitative secondary in the form of education and health data and population data in the Subdistrict of Subdistrict from 2010 to 2016. The analytical method used to project population numbers is the trend method and to analyze the needs of developing the provision of health and education facilities based on the urban settlement environmental planning guidelines of the 1979 Ministry of Public Works and the Indonesian National Standard. The results showed the condition of educational facilities infrastructure based on the population in 2016; at the kindergarten level it was not sufficient and the distribution was not evenly distributed, while the level of elementary school, junior high school and senior high school level was sufficient. The Condition of Kindergarten Schools in 2022 additional 66 TK and elementary school buildings need to be added to 5 units, junior and senior high school and high school and equivalent not to be added. Health facilities in 2016 are inadequate, such as auxiliary health centers, maternity homes and laboratories, hospitals, doctors' practices, pharmacies / drugstores and other facilities are sufficient and there are even health facilities that are more than what is supposed to be like hospitals, doctors' practices and pharmacies. Health facilities that need to be added in order to get optimal public health services in 2022 are 1 unit puskesmat, 14 posyandu units, 15 units of auxiliary health centers, 3 units of laboratories, 3 units of maternity homes and 10 units of treatment centers.

Kata Kunci :

ABSTRAK: Tujuan penelitian ini adalah untuk mengalisis kondisipada saat ini (2016)

Kebutuhan Fasilitas danuntuk memproyeksikebutuhanprasarana pendidikan, dan kesehatandi Kecamatan Selong Kabupaten Lombok Timur sampai tahun 2022. Data yang digunakan adalahdatasekunder yang bersifat kuantitatif berupa dataprasaranapendidikan dan kesehatan serta data jumlah penduduk KecamatanSelong dari tahun 2010 sampai tahun 2016. Metode analisis yang digunakan untuk memproyeksi jumlah penduduk adalah dengan metode trend dan untuk menganalisiskebutuhan mengembangan penyediaanprasaranafasilitas pendidikandankesehatan berdasarkan atas standar pedoman perencanaan lingkungan permukiman kota dari Departemen Pekerjaan Umum Cipta Karya Tahun 1979 dan Standar Nasional Indonesia. Hasil penelitian menunjukanKondisi prasarana fasilitas pendidikan berdasarkan jumlah penduduk tahun 2016;pada tingkat TK belum mencukupi dan penyebarannya tidak merata, sedangkan tingkat Sekolah Dasar, Sekolah Menengah Pertama dan Tingkat Sekolah menengah Atas dan sederajat sudah mencukupi.Kondisi Prasaran Sekolah Taman Kanak-kanak pada tahun 2022 perlu penambahan 66 unit Gedung sekolah TK dan Sekolah dasar perlu penambahan 5 unit,Sekolah SMP dan Sederajat dan SMA dan sederajat tidak perlupenambahan.Fasilitas kesehatan pada tahun 2016 belum memadai, seperti puskesmas pembantu, rumah bersalin dan laboratorium, sedang rumah sakit, praktek dokter, apotik/toko obat dan fasilitas lainnya sudah mencukupi bahkan ada fasilitas kesehatan yang melebihi dari apa yang seharusnya seperti rumah sakit, praktek dokter dan apotik. Fasilitas kesehatan yang perlu ditambah agar dapat pelayan kesehatan masyarakat secara optimalpada tahun 2022 adalah puskesmat sebanyak 1 unit, posyandu sebanyak 14 unit, puskesmas pembantu 15 unit, laboratorium 3 unit, rumah bersalin 3 unit dan balai pengobatan 10 unit. 
|2M.Afwi, Ade Paranata, PutuKarismawan,LufukFadliyanti /AnafisisKebutuhan.....

Corresponding Author:

Alamat : Program StudiEkonomi Pembangunan, Fakultas Ekonomi dan Bisnis, Universitas Mataram, Jln. Majapahit No. 62 Mataram.

e-mail: alwi@gmail.com

2019, EKONOBIS All right reserved 


\section{PENDAHULUAN}

\section{Latar Belakang}

Pertumbuhan (growth) merupakan ukuran utama keberhasilan pembangunan, dan hasil pertumbuhan ekonomi akan dapat pula dinikmati masyarakat sampai di lapisan paling bawah, baik dengan sendirinya maupun dengan campur tangan pemerintah. Pertumbuhan harus berjalan secara beriringan dan terencana, mengupayakan terciptanya pemerataan kesempatan dan pembagian hasil-hasil pembangunan dengan lebih merata. Dengan demikian maka daerah yang miskin, tertinggal, tidak produktif akan menjadi produktif, yang akhirnya akan mempercepat pertumbuhan itu sendiri. Strategi ini dikenal dengan istilah "redistribution with growth". Pertumbuhan ekonomi daerah yang berbeda-beda intensitasnya akan menyebabkan terjadinya ketimpangan atau dispantas ekonomi dan ketimpangan pendapatan antar daerah. Kecamatan Selong merupakan ibu kota Kabupaten Lombok Timur, dengan demikian Kecamatan Selong dapat dikatakan sebagai pusat pertumbuhan ekonomi, pusat pemerintahan, pusat perdagangan barang dan jasa dan administrasi. Oleh karena itu Kecamatan selong harus dapat memenuhi sarana prasarana untuk dapat melayani masyarakat secara optimal.

Untuk mempercepat

pertumbuhan, pembangunan dan mengurangi terjadinya ketimpanganketimpangansertamemberikanpelayananp ada masyarakat perlu diamati selama siklus ekonomi sedang berlangsung sehingga sinyalemen positif atau negatif yang mempengaruhi kinerja ekonomi makro secara umum dapat diantisipasi sedini mungkin diantaranya tesedia fasilitas pendidikan dan kesehatan yang memadai.

Berdasarkan keadaan di atas, maka kecamatan selong termasuk yang terpadat penduduk, pusat pertumbuhan, pendidikan, pemerintahan dan merupakan ibu kota dari Kabupaten Lombok Timur. Berdasarkan posisi ini maka kecamatan Selong harus memiliki sarana dan prasarana untuk dapat melayani masyrakat, baik dari segi social maupun dari segi ekonomi berdasarkan pertumbuhan jumlah penduduk

\section{Perumusan Masalah}

Berdasarkan uraian yang telah dikemukakan dari latar belakang di atas, maka peneliti merumuskan beberapa permasalahan yang akan diteliti dan diamati dalam penelitian adalah sebagai berikut: 
1. Bagaimanakah gambaran wilayah Kecamatan Selong Kabupaten Lombok Timur pada tahun 2016

2. Bagaimanakah kebutuhan sarana dan prasarana pendidikan dan kesehatan di Kecamatan Selong Kabupaten Lombok Timur sampai tahun 2022

\section{Tujuan Penelitian}

Bertitik tolak dari latar belakang dan permasalahan Kecamatan Selong sebagai pusat pertumbuhan di Kabupaten Lombok Timur, maka tujuan dari penelitian ini bertujuan sebagai berikut:

1. Menggambarkan keadaan wilayah pusat pertumbuhan di Kecamatan Selong Kabupaten Lombok Timur.

2. Untuk menganalisis kebutuhan pengembangan penyediaan prasarana pendidikan, kesehatan pada wilayah pusat pertumbuhan di Kecamatan Selong Kabupaten Lombok Timur sampai tahun 2022

\section{TINJAUAN PUSTAKA}

\section{Pertumbuhan Ekonomi dan \\ Perkembangan Ekonomi Wilayah}

Pertumbuhan ekonomi adalah proses kenaikan output per kapita dalam jangka panjang. Di sini, proses mendapat penekanan karena mengandung unsur dinamis. Para teoretikus ilmu ekonomi pembangunan masa kini, masih terus menyempurnakan makna, hakikat dan konsep pertumbuhan ekonomi. Para teoretikus tersebut menyatakan bahwa pertumbuhan ekonomi tidak hanya diukur dengan penambahan PDB dan PDRB saja, tetapi juga diberi bobot yang bersifat immaterial seperti kenikmatan, kepuasan, dan kebahagiaan, dengan rasa aman dan tenteram yang dirasakan masyarakat luas (Arsyad, 1999).

Pertumbuhan ekonomi (economic growth) bertautan erat dengan peningkatan produksi barang dan jasa, yang antara lain diukur dengan besaran yang disebut produk iastry bruto (PDB) pada aras nasional dan produk iastry regional bruto (PDRB) untuk daerah, baik propinsi maupun Kabupaten/Kota. BPS (2000) menyebut pertumbuhan ekonomi sebagai pertumbuhan produksi riil, baik secara iast maupun totalitasnya. Disebut pertumbuhan produksi riil karena harga yang digunakan dalam menilai suatu produksi dari tahun ke tahun menggunakan harga pada tahun tertentu sehingga perubahan harga (inflasi) tidak mernpengaruhi nilai produksinya. Penilaian ini dapat dilakukan atas dasar harga berlaku (current price) pada tahun perhitungan, atau atas dasar harga konstan (constant price) dari suatu tahun 
yang dipilih sebagai tahun dasar (base year).

Wijaya dalam Joni

mengemukakan dua konsep pertumbuhan ekonomi: (1) pertumbuhan ekonomi adalah proses di mana terjadi kenaikan produk nasional bruto riil atau pendapatan nasional riil. Perekonomian dikatakan tumbuh atau berkembang apabila terjadi pertumbuhan output riil. Output riil suatu perekonomian statis juga tetap konstan atau mengalami penurunan sepanjang waktu.

Ini berarti perekonomian statis atau mengalami penunman. Penurunan merupakan perubahan industry, sedang pertumbuhan adalah perubahan positif. (2) Pertumbuhan ekonomi terjadi apabila ada kenaikan output per kapita. Dalam hal ini pertumbuhan ekonomi menggambarkan kenaikan taraf hidup yang diukur dengan output riil per orang. Oleh karena itu pertumbuhan ekonomi terjadi apabila tingkat kenaikan output riil total lebih besar daripada tingkat pertumbuhan. Sebaliknya terjadi penurunan taraf hidup iast bila laju kenaikan jumlah penduduk lebih cepat dari pada laju pertumbuhan output riil total.

\section{Pengertian Sarana Dan Prasarana}

\section{Pendidikan}

Pengertian sarana dan prasarana pendidikan menurut Tim Perumus Penyusun Pedoman Pembukuan Media Pendidikan Departemen Pendidikan Dan Kebudayaan, dibedakan sesuai dengan fungsinya, yaitu:

1. Sarana pendidikan adalah semua fasilitas yang diperlukan dalam proses belajar mengajar, baik yang bergerak maupun yang tidak bergerak agar pencapaian tujuan pendidikan dan berjalan dengan lancar, teratur, efektif dan efisien.

2. Prasarana pendidikan adalah fasilitas yang secara tidak langsung menunjang jalannya proses pendidikan, seperti : halaman, kebun atau taman sekolah, jalan menuju ke sekolah, tata tertib sekolah, dan sebagainya.

\section{Pengertian Fasilitas Pelayanan Kesehatan}

Fasilitas pelayanan kesehatan adalah suatu alat dan/atau tempat yang digunakan untukmenyelenggarakan upaya pelayanan kesehatan, baik promotif, preventif, kuratif maupun rehabilitatif yang dilakukan oleh Pemerintah, pemerintah daerah, dan/atau masyarakat. Pembangunan fasilitas kesehatan bukanlah melulu kewajiban pemerintah, namun sangat diperlukan peran serta aktif masyarakat termasuk swasta sebagai mitra pemerintah. Peran 
pemerintah dalam hal ini lebih dititikberatkan pada pembinaan, pengaturan dan pengawasan untuk terciptanya pemerataan pelayanan kesehatan dan tercapainya kondisi yang serasi dan seimbang antara upaya kesehatan yang dilaksanakan oleh pemerintah dan masyarakat termasuk swasta. Sarana pelayanan medik swasta dapat berupa rumah sakit, klinik, poliklinik/balai pengobatan, praktik bersama maupun praktik mandiri/privat.

\section{METODE PENELITIAN}

\section{Jenis Penelitian}

Jenispenelitian yang digunakan adalah penelitian deskriptif, yaitu suatu metode dalam meneliti status kelompok manusia, suatuobjek, suatukondisi, suatu system pemikiran ataupun suatu peristiwa pada masa sekarang guna membua tdiskripsi, gambaran atau lukisan secara sistimatis, factual dan akurat mengenai fakta-fakta serta hubungan antara yang diselidiki, dianalisis kemudian disimpulkan. (Nazir, 1999: 63).

\section{Lokasi Penelitian}

Penelitian ini akan dilakukan di Kecamatan Selong, yang terdiriatas 12 Kelurahan/Desa. Pemilihan Kecamatan Selong ini dengan alas an bahwa kecamatan ini adalah merupakan sebagai pusat pertumbuhan, pusat pemrintahan dan pusat perdagangan barang dan jasa serta pusat pemerintahan.

\section{Metode Pengumpulan Data}

Mengumpulan data dilakukan dalam penelitian ini adalah metode kasus (case study) yaitu penelitian tentang suatu status subjek yang berkenaan dengan suatu pase spesifik atau khas dari keseluruhan personalitas di mana subjek ini terdiri dari kelompok, lembaga maupun masyarakat yang tujuannya untuk memberikan gambaran secara mendetail.

\section{Jenis dan Sumber Data}

Data yang digunakan dalam penelitian inia dalah data primer dan data sekunder diperoleh melalui dokumentasi dari instansi terkait, yaitu: Kantor Bappeda Kabupaten Lombok Timur, data BPS Kecamatan Selong dalam angka, meliputi: data kependudukan, pendidikan, kesehatan, fasilitas fisik dan prasarana pendidikan dan kesehatan, peta wilayah administrasi Kecamatan Selong dan peta wilayah pusat pertumbuhan di Kecamatan Selong Kabupaten Lombok Timur.

\section{Teknik Analisis Data}

1. Pendekatan yang digunakan untuk memproyeksikan jumlah penduduk dalam beberapa tahun kedepan adalah dengan metode trend 
(Pratama Raharja dan Mandala

Manurung). Metode ini memiliki rumus sebagai berikut:

$P n=P o(1+r)^{n}$

Dimana:

$\mathrm{Pn}=J$ umlah penduduk pada tahun ke-n

Po = Jumlah penduduk pada tahun awal

$r=$ Rata-rata proporsi kenaikan penduduk dan penyerapantenaga kerja setiap tahunnya (\%) $n=$ Periode waktu (tahun ke-n)
2. Pendekatan yang digunakan untuk menganalisis kebutuhan pengembangan pola penyediaan sarana dan prasarana fasilitas pendidikan kesehatan berdasarkan atas standar pedoman perencanaan lingkungan permukiman kota dari Departemen Pekerjaan Umum Direktorat Cipta Karya Tahun 1979 dalam Erwin Harahap 2009, yaitu dengan rumus sebagai berikut:

a. Fasilitas Pendidikan Jumlah Penduduk

Jumlah Penduduk

1.000 Jiwa

$x 1$ unit fasilitas TK = Jumlah fasilitas TK

Jumlah Penduduk 1.600 Jiwa

Jumlah Penduduk 4.800 Jiwa x 1 unit fasilitas SMP = Jumlah fasilitas SMP.....(3.3)

Jumlah Penduduk 1.000 Jiwa x 1 unit fasilitas SMU = Jumlah fasilitas SMU...(3.4)

Tabel 1.Pedoman dalam menghitung Kebutuhansarana dan prasaranaPendidikan

\begin{tabular}{|c|c|c|c|c|c|}
\hline $\mathbf{N}$ & $\begin{array}{l}\text { Tingkatan } \\
\text { Sekolah }\end{array}$ & $\begin{array}{l}\text { Jangkaua } \\
\text { n } \\
\text { Penduduk }\end{array}$ & $\begin{array}{c}\text { Radius } \\
\text { Pencapaian }\end{array}$ & $\begin{array}{l}\text { Standar Kuota } \\
\text { setiap unit }\end{array}$ & Lokasi \\
\hline 1 & TK & 1250 jiwa & 500 meter & $1 \mathrm{TK}=80$ siswa & $\begin{array}{l}\text { Di tengah-tengahkeluarga penduduk, } \\
\text { tidak menyebrang jalan raya, } \\
\text { bergabung dengan taman }\end{array}$ \\
\hline 2 & SD & 1600 jiwa & 1000 meter & $1 \mathrm{SD}=240$ siswa & $\begin{array}{l}\text { Berlokasi di tengah keluarga } \\
\text { penduduk. }\end{array}$ \\
\hline 3 & SMP & 4800 jiwa & 1000 meter & $\begin{array}{l}1 \mathrm{SMP}=240 \\
\text { jiwa }\end{array}$ & $\begin{array}{l}\text { Tidak harus di lingkungan } \\
\text { permukiman tetapi dapat dijangkau } \\
\text { dengan kendaraan umum dan } \\
\text { disatukandengan lapangan olahraga }\end{array}$ \\
\hline by & darapuspa & $\begin{array}{l}4800 \text { jiwa } \\
\text { agustin.bl }\end{array}$ & $\begin{array}{l}3000 \text { meter } \\
\text { gspot.com }\end{array}$ & $\begin{array}{l}1 \text { SMA }=720 \\
\text { jiwa }\end{array}$ & $\begin{array}{l}\text { Tidak selalu di pusat lingkungan } \\
\text { tetapi dapat dijangkau oleh } \\
\text { kendaraan umum. }\end{array}$ \\
\hline
\end{tabular}


b. FasilitasKesehatan

Jumlah Penduduk

60.000 Jiwa $\times 1$ unit fasilitas Rumah Sakit Type

Jumlah Penduduk

30.000 Jiwa

x 1 unit fasilitas Puskesmas

Jumlah Penduduk

6.000 Jiwa

$\times 1$ unit fasilitas Pustu

Jumlah Penduduk

30.000 Jiwa

x 1 unit fasilitas Laboratorium.

Jumlah Penduduk

30.000 Jiwa

$x 1$ unit fasilitas Bersalin

Jumlah Penduduk

5.000 Jiwa

x 1 unit fasilitas Praktek Dokter.

Jumlah Penduduk

30.000 Jiwa

$x 1$ unit fasilitas Apotik

Jumlah Penduduk

30.000 Jiwa

x 1 unit fasilitas Apotik

Jumlah Penduduk

10.000 Jiwa

x 1 unit fasilitas Balai Pengobatan

Tabel 2. Standar Pedoman Perencanaan Sarana Kesehatan

\begin{tabular}{llcc}
\hline No & \multicolumn{1}{c}{$\begin{array}{c}\text { Jenis Bangunan } \\
\text { (Unit) }\end{array}$} & $\begin{array}{c}\text { Minimum } \\
\text { Penduduk } \\
\text { Pendukung } \\
\text { (Jiwa) }\end{array}$ & $\begin{array}{c}\text { Luas Lahan } \\
\left(\mathbf{m}^{\mathbf{2}}\right)\end{array}$ \\
\hline 1 & Rumah Sakit Type C & 60.000 & $2400 \mathrm{~m}^{2}$ \\
2 & Puskesmas & 30.000 & $1200 \mathrm{~m}^{2}$ \\
3 & Puskesmas Pembantu & 6.000 & $600 \mathrm{~m}^{2}$ \\
4 & Laboratorium & 30.000 & $350 \mathrm{~m}^{2}$ \\
5 & Rumah Bersalin & 30.000 & $1.000 \mathrm{~m}^{2}$ \\
6 & Balai Pengobatan & 10.000 & $300 \mathrm{~m}^{2}$ \\
7 & Praktek Dokter & 5.000 & $\mathrm{~m}^{2}$ \\
8 & Apotik & 30.000 & $350 \mathrm{~m}^{2}$ \\
\hline
\end{tabular}

Sumber: Dep. PIT. Dir. Cipta Karya Tahun 1979

HASIL DAN PEMBAHASAN

Gambaran Sarana dan Prasarana

Pendidikan Di Kecamatan Selong Pada

Tahun 2016

Jumlah penduduk Kecamatan Selong pada

tahun 2016 sebanyak 90.316 jiwa yang tersebaran pada 12 desa/ kelurahan dengan tingkat pertumbuhan

ekonomi sebesar 5,7 \%. Penyebaran jumlah penduduk

Adapun jumlah Prasarana pendidikan mulai dari taman kanak (TK) sampai sekolah menengah lanjutan atas (SLTA) seperti nampak pada tabel berikut ini : 
Tabel 3. Jumlah Sekolah Menurut Jenjang Pendidikan Per Desa di Kecamatan Selong Tahun 2016

\begin{tabular}{|l|l|l|l|l|l|l|l|}
\hline Desa & PAUD & TK & SD & MI & SMP & MTS & $\begin{array}{l}\text { Jumlah Penduduk } \\
\text { (jiwa) }\end{array}$ \\
\hline 1.Denggen & 2 & - & - & - & 2 & - & 3.580 \\
\hline 2.Kelayu Jorong & - & 1 & 5 & - & 2 & - & 5.277 \\
\hline 3.Kembang Sari & 5 & - & 4 & 1 & - & 1 & 5.983 \\
\hline 4.Majidi & 2 & 3 & 4 & - & 1 & 1 & 8.407 \\
\hline 5.Rakam & 4 & - & 3 & 1 & 1 & - & 6.521 \\
\hline 6.Pancor & 5 & 2 & 4 & 4 & - & 5 & 17.293 \\
\hline 7.Sekarteja & 3 & - & 5 & 1 & - & - & 11.220 \\
\hline 8.Sandubaya & 4 & 5 & 3 & 2 & 4 & - & 6.077 \\
\hline 9.Khusus Kota Selong & 4 & - & 7 & 1 & - & - & 12.003 \\
\hline 10.Kelayu Selatan & 1 & - & 3 & - & - & 2 & 5.342 \\
\hline 11.Kelayu Utara & - & 2 & 5 & - & - & - & 5.602 \\
\hline 12.Denggen Timur & 2 & - & 3 & 1 & 1 & - & 3.011 \\
\hline $\begin{array}{l}\text { Jumlah Sekolah dan } \\
\text { Penduduk }\end{array}$ & 31 & 13 & 46 & 11 & 11 & 9 & 90.316 \\
\hline
\end{tabular}

Lanjutan Tabel Tabel 3.

\begin{tabular}{|l|l|l|l|l|l|l|}
\hline Desa & $\begin{array}{l}\text { SD-SMP } \\
\text { Satap }\end{array}$ & $\begin{array}{l}\text { SMP } \\
\text { Terbuka }\end{array}$ & SMA & SMK & MA & $\begin{array}{l}\text { Jumlah } \\
\text { Penduduk } \\
\text { (jiwa) }\end{array}$ \\
\hline 1.Denggen & & - & - & - & - & 3.580 \\
\hline 2.Kelayu Jorong & - & - & 3 & - & - & 5.277 \\
\hline 3.Kembang Sari & - & - & - & - & 1 & 5.983 \\
\hline 4.Majidi & - & - & - & - & 1 & 8.407 \\
\hline 5.Rakam & - & - & - & 1 & - & 6.521 \\
\hline 6.Pancor & - & - & - & 1 & 5 & 17.293 \\
\hline 7.Sekarteja & - & - & - & - & - & 11.220 \\
\hline 8.Sandubaya & - & - & 1 & 1 & - & 6.077 \\
\hline 9.Khusus Kota Selong & - & - & 3 & - & 1 & 12.003 \\
\hline 10.Kelayu Selatan & - & - & - & - & 2 & 5.342 \\
\hline 11.Kelayu Utara & - & - & - & - & - & 5.602 \\
\hline 12.Denggen Timur & - & - & - & - & - & 3.011 \\
\hline $\begin{array}{l}\text { Jumlah Sekolah dan } \\
\text { Penduduk }\end{array}$ & - & - & 7 & 3 & 10 & 90.316 \\
\hline
\end{tabular}

Sumber:BPS dalam Kecamatan Selong Dalam Angka 2017

Berdasarkan pada tabel di atas terlihat pada Desa Danggeng hanya terdapat sekolah PAUD dan SMP sedang jenis sekolah lainnya tidak. Untuk dapat menampung tamatan PAUD dan maka perlu didirikan sekolah TK dan SD dimana pada usia TK dan SD terlalu jauh untuk bersekolah di Desa tetangga lainnya. 
Apabila dilihat perbandingan antara jumlah sekolah pada setiap jenjang pendidikan tidak sebanding dengan jenjang pendidikan di diatasnya misal jumlah sekolah PAUD 31 sedangkan TK hanya 13 sekolah. Sekolah SD berjumlah 46 sedang jenjang berikutnya yaitu SMP hanya 11 sekolah dan MI juga 11 . Pada tabel tersebut di atas terlihat bahwa lokasi dari masing masing sekolah belum tersebar secara merata pada 12 Desa/ kelurahan di Kecamatan Selong.

\section{Gambaran Sarana dan Prasarana Kesehatan Di Kecamatan Selong pada tahun 2016}

Dalam melayani kebutuhan pelayanan masyarakat di bidang kesehatan di Kecamatan Selong Kabupaten Lombok Barat dilakukandengan pola penyediaan sarana kesehatan. Pada tahun 2016 Kecamatan Selong telah memiliki beberapa unit prasaranakesehatan seperti pada tabel berikut ini :

Tabel 4. Jumlah Fasilitas Kesehatan di Kecamatan Selong Kabupaten Lombok Timur 2016

\begin{tabular}{|l|l|l|l|l|l|}
\hline No & Jenis Fasilitas & $\begin{array}{l}\text { Bangunan } \\
\text { Pemerintah } \\
\text { (unit) }\end{array}$ & $\begin{array}{l}\text { Bangunan } \\
\text { Swasta } \\
\text { (Unit) }\end{array}$ & Jumlah & Seharusnya \\
\hline 1 & Rumah Sakit Umum & 1 & 2 & 3 & 2 \\
\hline 2 & Poliknilik & 5 & - & 5 & \\
\hline 3 & Puskesmas & 2 & - & 2 & 2 \\
\hline 4 & Puskesmas Pembantu & & - & - & 15 \\
\hline 5 & Balai Pengobatan & - & - & - & 3 \\
\hline 6 & Praktek Dokter & - & 24 & 24 & 18 \\
\hline 7 & Apotik/toko obat & 12 & - & 12 & 3 \\
\hline 8 & Posyandu & 64 & - & 64 & 72 \\
\hline 9 & $\begin{array}{l}\text { Praktek Bidan/Rumah } \\
\text { bersalin }\end{array}$ & - & 10 & 10 & 10 \\
\hline 10 & Polindes & & 9 & 9 & \\
\hline
\end{tabular}

Sumber : Kecamatan Selong Dalam Angka 2016

Berdasarkan pada tabel diatas dapat diketahui bahwa kondisi fasilitas kesehatan pada tahun 2016 masih banyak yang tidak ada di Kecamatan Selong dan seharusnya ada seperti dalam tabel berikut ini

Tabel 5.Fasilitas Kesehatan yang Tidak ada dan Seharusnya ada di Kecamatan Selong KabupatenLombok Timur pada tahun 2016

\begin{tabular}{|l|l|c|}
\hline No & $\begin{array}{l}\text { Fasilitas Kesehatan Yang tidak } \\
\text { pada tahun 2016 }\end{array}$ & $\begin{array}{c}\text { Fasilitas kesehatan yang harus } \\
\text { ada pada tahun 2016 (Unit) }\end{array}$ \\
\hline 1 & Puskesmas Pembantu & 15 \\
\hline 2 & Balai Pengobatan & 3 \\
\hline
\end{tabular}

Sumber : Hasil Analisis 
Pada tabel di atasdapat pula diketahu fasilitas keshatan yang sudah ada kekurangan dan ada pula yang kelebihan. Adapun yang kurang ada pasilisitas posyandu sebanyak 64 unit seharusnya 72 unit,sedangkan yang berlebihan seperti;rumah sakit sebanyak 3 unit seharus 2 unit, praktek dokter sebanyak 24 unit seharusnya 18 unit dan apotik sebanyak 12 unit seharusnya 3 unit. Fasilitas kesehatan lainnya yang ada adalah poliknilik sebanyak 5 unit dan polindes 9 unit di Kecamatan Selong pada tahun 2016.

\section{Analisis Proyeksi Perkembangan}

Penduduk.

Adapun masalah penduduk dari tahun ke tahun selalu mendapatkan perhatian yang serius, baik pemerintah pusat maupun pemerintah daerah termasuk Kecamatan Selong Kabupaten Lombok Timur. Hal ini disebabkan masalah penduduk berkaitan dengan berbagai bidang kehidupan seperti kesehatan, pendidikan dan perumahan. Untuk dapat merencanakan kebuuhan fasilitas sarana prasarana pendidikan dan kesehatan, maka data data kependudukan sangat diperlukan.

Jumlah penduduk di masa mendatang dapat diperkirakan pada beberapa tahun yang akan datang secara angka-angka. Hal ini dapat dilakukan dengan menggunakan data-data jumlah pendudukdi suatu daerah.Analisisi perkembangan penduduk sangat diperlukan karena penduduk merupakan subjek dan objek dari pada pembangunan yang berkelanjutan. Adapun hasil perhitungan proyeksi jumlah penduduk Kecamata Selong Kabaten Lombok Timur sampai tahun 2022 dapat dilihat pada tabel berikut :

Tabel 6. Proyeksi Penduduk Kecamatan Selong Kabupaten Lombok Timur $2017-2022$

\begin{tabular}{|c|c|r|r|r|}
\hline No & Tahun & Jumlah Penduduk (Jiwa) & $\begin{array}{l}\text { Pertumbuhan } \\
\text { (jiwa) }\end{array}$ & \multicolumn{2}{l|}{$\begin{array}{l}\text { Pertumbuhan } \\
\text { (\%) }\end{array}$} \\
\hline 1 & 2017 & 91488 & - & 1,50 \\
\hline 2 & 2018 & 92860 & 1372 & 1,53 \\
\hline 3 & 2019 & 94282 & 1422 & 1,43 \\
\hline 4 & 2020 & 95634 & 1352 & 1.51 \\
\hline 5 & 2021 & 97076 & 1442 & 1,49 \\
\hline 6 & 2022 & 98519 & 1443 & \\
\hline
\end{tabular}

Hasi proyeksi kependudukan di Timur samapai tahun 2022 diperkirakan Kecamatan Selong Kabupaten Lombok 98.519 jiwa. 
Hasil proyeksi penduduk per Desa/ Selong dapat dilihat pada tabel berikut ini Kelurahan pada tahun 2022 di Kecamatan

Tabel 7. Proyeksi Penduduk Desa/Kelurahan di Kecamatan Selong sampai Tahun 2022

\begin{tabular}{|c|c|c|c|c|}
\hline Desa/Kelurahan & Denggen & Kelayu Joron & $\begin{array}{c}\text { Kembang } \\
\text { Sari }\end{array}$ & Majidi \\
\hline $\begin{array}{c}\text { Proyeksi penduduk thn } \\
2022 \text { (Jiwa) }\end{array}$ & 3914 & 65736 & 6542 & 9192 \\
\hline Desa/Kelurahan & Karam & Pancor & Seketeja & Sandubaya \\
\hline $\begin{array}{c}\text { Proyeksi penduduk thn } \\
2022 \text { (Jiwa) }\end{array}$ & 7088 & 18909 & 12268 & 6645 \\
\hline $\begin{array}{c}\text { Desa/Kelurahan } \\
\text { Khusus Kota } \\
\text { Selong }\end{array}$ & Kelayu Selatan & Kelayu Utara & $\begin{array}{c}\text { Denggen } \\
\text { Timur }\end{array}$ \\
\hline $\begin{array}{c}\text { Proyeksi penduduk thn } \\
2022 \text { (Jiwa) }\end{array}$ & 13124 & 5841 & 6125 & 3292 \\
\hline
\end{tabular}

Sumber : Data diolah Dari Kecamatan Selong Dalam Angka

\section{Analisis Kebutuhan Sarana Pendidikan}

Keberhasilan penyelenggaraan pendidikan tidak terlepas dari tersedianya sarana pendidikan yang memadai di samping juga harus didukung oleh tenaga pendidik yang memegang peranan utama untuk terselenggaranya proses belajar mengajar. Oleh karenanya ketersediaan fasilitas pelayanan untuk pendidikan harus selalu disesuaikan dengan kebutuhan penduduk yang mana dari waktu ke waktu selalu berkembang, dengan demikian penduduk dapat terlayani dan fasilitas yang tersedia dapat berfungsi secara optimal. Berdasarkan proyeksi penduduk tahun 2022 sebesar 98519 jiwa maka pasilitas pendidikan dapat diproyeksikan seperti Nampak pada tabel berikut :

Tabel 8.Proyeksi Jumlah Kebutuhan sarana dan prasarana Fasilitas Pendididikan Kecamatan Selong Kabupaten Lombok Timur tahun 2022

\begin{tabular}{|l|l|l|l|l|}
\hline No & \multicolumn{1}{|c|}{$\begin{array}{c}\text { Jenis } \\
\text { Fasilitas }\end{array}$} & \multicolumn{1}{|c|}{ Jumlah (Unit) } & \multicolumn{1}{|c|}{ Jumlah Kelas } & \multicolumn{1}{c|}{$\begin{array}{c}\text { Jumlah Murid } \\
\text { (Orang) }\end{array}$} \\
\hline 1 & TK & 79 & 158 & 6.320 \\
\hline 2 & SD & 60 & 360 & 14,400 \\
\hline 3 & SMP & 20 & 120 & 4.800 \\
\hline 4 & SMA & 20 & 360 & 14.400 \\
\hline
\end{tabular}

Sumber : Hasil Analisis

Berdasarkan pada tabel di atas terlihat bahwa jumlah Proyeksi Sarana prasarana fasilitas pendidikan menurut proyeksi tahun 2022dari tingkat taman Kanak Kanak (TK) sebanyak 79 sekolah , SD sebanyak 61 , SMP sebanyak 20 dan 
Tingkat SMA sebanyak 20 unit sekolah . Sedangkan pada tahun 2016 jumlah sarana prasaran fasilitas pendidikan untuk TK sebanyak 13 unit sekolah , SD ditambah MI sebanyak 57 unit sekolah , SMP ditambah MTS sebanyak 20 unit sekolah sedangkan SMA dan sederajat sebanyak 20 unit sekolah dengan demikian untuk fasilitas SD dan sederajat sampai SMA dan sederajat sudah memebuhi kebutuhan sejak tahun 2016, sedangkam fasilitas pendidikan TK ditambah Paud masih kurang yag hanya 144 unit yang terdiri dari fasilitas sekolah Paud 31 unit dan fasilitas TK sebanyak 13 unit sekolah. Untuk melihat penyebaran Jumlah sarana parasaran fasilitas pendidikan menurut Desadan Kelurahan berdasarkan jumlah penduduk tahun 2022 nampak pada tabel berikut :

Tabel 9. Proyeksi KebutuhanPrasarana Fasilitas Pendidikan di Desa/Kelurahan yang ada di Kecamatan Selong Kabupaten Lombok Barat tahun 2022

\begin{tabular}{|l|l|l|l|l|l|l|}
\hline No & Desa/Kelurahan & $\begin{array}{l}\text { Penduduk } \\
\text { Tahun 2022 }\end{array}$ & & \multicolumn{4}{|l|}{ Jumlah Jenis Bangunan } \\
\cline { 5 - 7 } & & (jiwa) & & SD & SMP & SMA \\
\hline 1 & Denggen & 3914 & 3 & 2 & 1 & 1 \\
\hline 2 & Kelayu Jorong & 5736 & 3 & 3 & 1 & 1 \\
\hline 3 & Kembang Sari & 6542 & 5 & 4 & 1 & 1 \\
\hline 4 & Majidi & 9192 & 7 & 6 & 2 & 2 \\
\hline 5 & Karam & 7088 & 5 & 4 & 1 & 1 \\
\hline 6 & Pancor & 18909 & 15 & 12 & 4 & 4 \\
\hline 7 & Sekerteja & 12268 & 9 & 7 & 2 & 2 \\
\hline 8 & Sandubaya & 6645 & 5 & 4 & 1 & 1 \\
\hline 9 & Khusus Kota Selong & 13124 & 10 & 8 & 3 & 3 \\
\hline 10 & Kelayu Selatan & 5841 & 5 & 4 & 1 & 1 \\
\hline 11 & Kelayu Utara & 6122 & 5 & 4 & 1 & 1 \\
\hline 12 & Denggen Timur & 3292 & 3 & 2 & 1 & 1 \\
\hline & Jumlah & & 79 & 60 & 20 & 20 \\
\hline
\end{tabular}

Sumber : Data Hasil Analisis

Jika dibandingkan dengan kondisi tahun 2022, fasilitas pendidikan di Kecamatan Selong Kabupaten Lombok Timur menurut Desa dan Kelurahan tahun 2016 tabel dengan hasil analisis kebutuhan
Penyediaan fasilitas pendidikan

Kecamatan Selong Kabupaten Lombok

Timur menurut Desa dan Kelurah terlihatpenyebarannya masing-masing pada fasilitas pendidikan sudah cukup merata tiap desa dan kelurahan. Hal ini dapat menjadi peningkatan kualitas 
pendidikan di Kecamatan Selong

Kabupaten Lombok Timur.

Berdasarkan dari hasil analisis kebutuhan sarana dan fasarana fasilitas pendidikan tahun 2022 dan jika dibandingkan dengan kondisi tahun 2007 maka dibutuhan penambahan fasilitas pendidikan seperti nampak pada tabel berikut ini :

Tabel10. Analisis Tambahan KebutuhanSarana Prasaranan Fasilitas Pendidikan Kecamatan Selong Kabupaten Lombok Timur Tahun 2022

\begin{tabular}{|l|l|c|c|c|c|c|}
\hline No & Jenis Bangunan & $\begin{array}{c}\text { Thn } \\
2022 \\
(\text { Unit })\end{array}$ & $\begin{array}{c}\text { Kondisi } \\
\text { Thn } \\
2016\end{array}$ & $\begin{array}{c}\text { Penambahan } \\
\text { Bangunan } \\
(\text { Unit })\end{array}$ & $\begin{array}{c}\text { Luas } \\
\text { Bangunan } \\
\left(\mathrm{m}^{2}\right)\end{array}$ & $\begin{array}{c}\text { Luas } \\
\text { Tanah } \\
\left(\mathrm{m}^{2}\right)\end{array}$ \\
\hline 1 & TK & 79 & 13 & 66 & 16.632 & 19.200 \\
\hline 2 & SD dan Sederajat & 60 & 57 & 3 & 1200 & 10.800 \\
\hline 3 & $\begin{array}{l}\text { SMP dan } \\
\text { Sederajat }\end{array}$ & 20 & 20 & - & - & - \\
\hline 4 & $\begin{array}{l}\text { SMA dan } \\
\text { Sederajat }\end{array}$ & 20 & 20 & - & - & - \\
\hline
\end{tabular}

Sumber : Hasil Analisis

Berdasarkan pada tabel di atas diketahui bahwa kebutuhanprasarana fasilitas pendidikan di Kecamatan Selong samapai tahun 2022 dan jika dibandingkan kondisi tahun 2016 , maka dibutuhkan penambahan fasilitas gedung sekolah Taman Kanak kanak (TK) sebanyak 66 unit, gedung sekolah Dasar (SD) sebanyak 3 unit,sedangkan Sekolah Menengah Pertama (SMP) dan Sekolah Menengah Atas (SMA) tidak perlu ada penambahan karena sudah mencukupi sejak tahun 2016, Berdasarkan kondisi jumlah penduduk tahun 2016 maka jumlah Sekolah Taman Kanak kanak (TK) seharusnya 72 Sekolah TK dan SD /sederajat 57 sedangkan SMP dan SMA sebanyak 19 unit Sekolah, dengan demikian pada tahun 2016 jum TK masih sangat kurangmencukupi. Sedangkan sekolah SD sampai dengan SMA sudah cukup terpenuhi pada tahun 2016.

Analisis Kebutuhan Saranadan rasarana Kesehatan Di Kecamatan Selongtahun 2022

Keberhasilan dalam kesehatan masyarakat tidak terlepas dari tersedianya prasaranafasilitas kesehatan yang memadai di samping juga harus didukung oleh tenaga medic yang memegang peranan utama untuk terselenggaranya pelayanan kesehatan masyarakat. Oleh karenanya ketersediaan fasilitas pelayanan untuk kesehatan harus selalu disesuaikan dengan kebutuhan penduduk yang mana dari waktu ke waktu selalu 
meningkat, dengan demikian penduduk dapat terlayani dan fasilitas yang tersedia dapat berfungsi secara optimal.
2022 maka pasilitas kesehatan dapat diproyeksikan seperti Nampak pada tabel berikut.

Berdasarkan proyeksi penduduk tahun

Tabel11. Analisisi Kebutuhan Prasarana Fasilitas Kesehatan Di Kecamatan Selong Kabupaten Lombok TimurTahun 2022

\begin{tabular}{|l|l|c|c|c|c|}
\hline No & \multicolumn{1}{|c|}{ Jenis Bangunan } & $\begin{array}{c}\text { Tahun 2022 } \\
\text { jumlah unit }\end{array}$ & $\begin{array}{c}\text { Tahun } \\
2016 \text { Unit }\end{array}$ & Penambahan(Unit) & $\begin{array}{c}\text { Luas Lahan } \\
\text { (M2) }\end{array}$ \\
\hline 1 & Rumah Sakit TV C & 2 & 3 & -1 & 0 \\
\hline 2 & Puskesmas & 3 & 2 & 1 & 1200 \\
\hline 3 & Poliknilik & & 5 & & \\
\hline 4 & Polindes & & 9 & & 0 \\
\hline 5 & Praktek Dokter & 19 & 24 & -5 & \\
\hline 6 & Praktek Bidan/ & & 10 & & 0 \\
\hline 7 & Posyandu & 78 & 64 & -9 & 9.600 \\
\hline 8 & Apotik /Toko Obat & 3 & 12 & 16 & 1.050 \\
\hline 9 & $\begin{array}{l}\text { Puskesmat } \\
\text { Pembantu }\end{array}$ & 16 & - & 3 & 3.000 \\
\hline 10 & laboratorium & 3 & - & 3 & 3.000 \\
\hline 11 & Rumah Bersalin & 3 & - & 10 & \\
\hline 12 & Balai Pengobatan & 10 & - & & \\
\hline
\end{tabular}

Sumber : Hasil Analisis Proyeksi

\section{KESIMPULAN DAN SARAN}

Berdasarkan hasil analisis kebutuhan pasarana fasilitas kesehatan di Kecamatan Selong Kabupaten Lombok Timur tahun 2022 pada tabel di atas dibutuhkan penambahan fasilitas puskesmas sebanyak 1 unit, Posyan sebanyak 14 unit, puskesmas pembantu 16 unit, laboratorium 3 unit, rumah bersalin 3 unit dan balai pengobatan, sementara rumah sakit, toko obat/ potik berdasrkan analisis di atas sudah memadai bahkan melebih dari yang seharusnya namun perlu ditingkatkan kualitas standar baku maupun standar pelayanan kualitasnya.

\section{Kesimpulan}

1. Gambaran sarana prasana fasilitas pendidikan pada tahun 2016 berdasarkan jumlah penduduk 90.316 jiwa adalah pada tingkat TK belum mencukupi dan penyebarannya tidak merata, sedangkan tingkat Sekolah Dasar (SD), Sekolah Menengah Pertama (SMP dan Sederajat) dan Tingkat Sekolah menengah Atas (SMA) dan sederajat sudah mencukupi.

2. Sarana dan Prasarana fasilitas pendidkan berdasarkan proyksi jumlah penduduk tahun 2022 sebesar 98.519 jiwa, untuk Sekolah Taman Kanak- 
kanak (TK) belum mencukupi dan perlu penambahan 66 unit Gedung sekolah TK dan Sekolah dasar (SD) perlu penambahan 3 unit fasilitas bangunan Sekolah. Untuk sekolah SMP dan Sederajat dan SMA dan sederajat tidak perlu ada penambahan karena sudah mencukupi.

3. Gambaran sarana prasarana kesehatan berdasarkan jumlah penduduk sebesar 90.316 adalah belum memadai dimana tidak fasilitas kesehatan puskesmas pembantu , rumah bersalin dan laboratorium sedang rumah sakit, praktek dokter, apotik/took obat dan fasilitas lainnya sudah cukup bahkan ada fasilitas kesehatan yang melebihi dari apa yang seharusnya seperti rumah sakit, praktek dokter dan apotik.

4. Prasarana kesehatan yang perlu ada penambahan agar dapat pelayan kesehatan masyarakat secara optimal pada tahun 2022 dengan proyeksi penduduk sebesar 98.519 jiwa adalah puskesmas sebanyak 1 unit, posyandu sebanyak 14 unit, puskesmas pembantu 16 unit,laboratorium 3 unit , rumah bersalin 3 unit dan balai pengobatan 10 unit.

\section{Saran}

Berdasarkan hasil penelitian dapat ditarik beberapa saran :

1. Berdasarkan hasil penelitian proyeksi jumlah penduduk, kebutuhan akan prasarana pendidikan dan kesehatan sampai tahun 2022 dalam penelitian ini, agar pemerintah Kecamatan Selong Kabupaten Lombok Timur yaitu Bappeda (Badan Perencanaan Pembangunan Daerah) merencanakan fasilitas sesuai hasil penelitian agar dapat melayani penduduk secara optimal dibidang pendidikan dan kesehatan,

2. Meskipun sarana prasarana pendidikan dan kesehatan sudah mencukupi maka perlu tetap ditingkat kualitas pelayanan dan sumberdaya manusia dalam bidang ini. 


\section{DAFTAR PUSTAKA}

BPS dalam Kecamatan Selong Dalam Angka 2017

Arsyad, Lincolin.1999. Pengantar perencanaan dan pembangunan ekonomi daerah. BPFE Yogyakarta

Djumino, Amin Nurman, dan Erwin Harahap, 2009, Analisis Kelayakan Investasi. Ditinjau dari Aspek Penganggaran Modal pada PT. Masterwood Indonesia,.

Joni Emirson. Alternative Penyelesaian Sengketa diluar Pengadilan. repository.usu.ac.id/bitstream/handle/123456789/28080/Reference.pdf?

Nazir, Mohammad.1999. Metode Penelitiaan. Jakarta: Erlangga. 